\title{
Avaliação de Fontes de Amônia para o Tratamento de Fenos de Gramíneas Tropicais.
} 2. Compostos Nitrogenados

\section{Ricardo Andrade Reis ${ }^{1}$, Luis Roberto de Andrade Rodrigues ${ }^{1}$, Kléber Tomás de Resende ${ }^{1}$, João Ricardo Alves Pereira², Ana Cláudia Ruggieri ${ }^{3}$}

\begin{abstract}
RESUMO - Este estudo foi desenvolvido para se avaliarem as alterações nos conteúdos de compostos nitrogenados dos fenos de braquiária decumbens (Brachiaria decumbnes Stapf) e jaraguá (Hyparrhenia rufa Ness Stapf) não-tratados, tratados com uréia (U - 5,4\% da MS), uréia (UL - 5,4\% da MS) mais labe-labe (Lablab purpureus L. Sweet, cv. Highworth-3,0\% da MS) ou amônia anidra (NH - $^{-}$ 3,0\% da MS). A aplicação de amônia anidra ou de uréia aumentou os teores de $\mathrm{N}$ total, $\mathrm{N}$ insolúvel em detergente neutro, $\mathrm{N}$ insolúvel em detergente ácido, $\mathrm{N}$ não-protéico e $\mathrm{N}$ amoniacal. A amonização diminuiu as relações $\mathrm{N}$ insolúvel em detergente neutro/N total e $\mathrm{N}$ insolúvel em detergente ácido/ $\mathrm{N}$ total e aumentou as relações $\mathrm{N}$ não-protéico/ $\mathrm{N}$ total, $\mathrm{N}$ amoniacal/ $\mathrm{N}$ total e os teores de $\mathrm{PB}$. $\mathrm{O} \mathrm{N}$ aplicado foi retido, principalmente, nas formas de NNP e N amoniacal.
\end{abstract}

Palavras-chave: amonização, amônia anidra, compostos nitrogenados, gramíneas tropicais, nitrogênio amoniacal, uréia

\section{Evaluation of Ammonia Sources to Tropical Grasses Hays Treatment. 2. Nitrogen Compounds}

\begin{abstract}
The experiment was conducted to evaluate the changes on the nitrogen compounds of the Brachiaria decumbens Stapf, jaraguá (Hyparrhenia rufa Ness Stapf) grasses hay, untreated, treated with urea (5.4\% DM), urea plus lab-lab (UL-5.4\% DM plus Lablab purpureus $\mathrm{L}$. Sweet, cv. Highworth-3.0\% DM) and anhydrous ammonia $\left(\mathrm{NH}_{3}-3.0 \% \mathrm{DM}\right)$. The chemical treatment with urea or $\mathrm{NH}_{3}$ increased the total $\mathrm{N}$, neutral detergent insoluble $\mathrm{N}$ 9NDIN), acid detergent insoluble N (ADIN), non nitrogen protein (NNP), and the ammonical nitrogen (AN) contents. Ammoniation decreased the NDIN/TN and ADIN/TN ratios. The chemical treatment increased the NNP/TN and NA/TN ratios, and the crude protein contents. The $\mathrm{N}$ applied as urea or $\mathrm{NH}_{3}$ was retained as NNP and in the ammoniacal form.
\end{abstract}

Key Words: ammoniation, chemical composition, nitrogen compounds, tropical grass, urea

\section{Introdução}

Nos sistemas de exploração econômica de ruminantes, é de suma importância a produção e utilização de volumosos de alta qualidade durante o período de escassez de forragem proveniente das pastagens.

No processo de fenação, existem dificuldades de ordem climática para a produção de fenos de alto valor nutritivo durante o verão, enquanto a produção de silagem implica em custo elevado, o que pode acarretar em baixa eficiência econômica de utilização destes alimentos.

A utilização de volumosos de baixo valor nutritivo, submetidos a tratamentos químicos, pode ser uma alternativa viável para suprir a demanda por volumosos durante o período de escassez de forragem proveniente das pastagens.

Entre os produtos químicos disponíveis, a utilização da amônia anidra ou da uréia como fonte de amônia tem- se mostrado eficiente em aumentar o valor nutritivo de volumosos (REIS et al., 1990b; BERGER et al., 1994).

Sem dúvida, o resultado mais consistente observado nas pesquisas sobre a amonização de volumosos é a elevação nos teores dos compostos nitrogenados, o que é devido ao conteúdo de $\mathrm{N}$ dos produtos usados, pois a $\mathrm{NH}_{3}$ possui $82,0 \%$ de $\mathrm{N}$, a água amônia, 25,0 de $\mathrm{N}$ e a uréia, $46,5 \%$ de $\mathrm{N}$ (SUNDSTOL e COXWORTH, 1984).

$\mathrm{Na}$ utilização de volumosos submetidos à amonização, é de suma importância a determinação da forma como o nitrogênio foi incorporado a forragem. De maneira geral, com a amonização observa-se elevação de 0,8 a 1,0 unidade percentual no conteúdo de $\mathrm{N}$ dos volumosos, correspondendo a 5,0 a 6,0 unidades de proteína bruta (SUNDSTOL e COXWORTH, 1984; BERGER et al., 1994).

De acordo com BUETTNER et al. (1982), DRYDEN e KEMPTON (1984), MASON et al.

\footnotetext{
1 Professor da FCAV/UNESP, 14870-000, Jaboticabal-SP. E.mail: rareis@fcav.unesp.br

2 Professor da Universidade Estadual de Ponta Grossa, 84010-300 - Ponta Grossa, PR.

3 Pesquisadora do Instituto de Zootecnia, 141160-000, Sertãozinho - SP. E.mail: ruggieri@izsp.br
} 
(1989a, 1989b), nos volumosos tratados com fontes de amônia, o N pode ser retido sob diferentes formas e, segundo KRISSHNAMOORTHY et al. (1982), SNIFFEN et al. (1992) e VAN SOEST e FOX (1992), as formas de $\mathrm{N}$ retido mais importantes em termos nutricionais são o $\mathrm{N}$ solúvel em água, o $\mathrm{N}$ amoniacal $\left(\mathrm{N}-\mathrm{NH}_{3}\right)$, o N retido na fração insolúvel em detergente neutro (NIDN) e o N retido na fração insolúvel em detergente ácido (NIDA).

Trabalhos de pesquisa conduzidos com volumosos de baixa qualidade submetidos à amonização evidenciam que a principal forma de retenção do $\mathrm{N}$ aplicado é a de $\mathrm{N}$ solúvel em água (SUNDSTOL e COXWORTH, 1984; BERGER et al., 1994) e também o N amoniacal (DRYDEN e KEMPTON, 1984, MASON et al., 1989a; 1989b, ROSA e REIS, 1995).

Estudos conduzidos com gramíneas tropicais mostraram aumento nos teores de nitrogênio total (NT) e de nitrogênio insolúvel em detergente ácido (NIDA), em resposta à amonização (REIS et al., 1990b, 1991).

A retenção do $\mathrm{N}$ aplicado varia em função da quantidade de amônia adicionada, sendo registrados maiores valores com o uso de doses menores de $\mathrm{NH}_{3}$ (SUNDSTOL e COXWORTH, 1984, REIS et al., 1990a, 1990b, 1991).

O experimento foi conduzido para se avaliarem as alterações nos teores de compostos nitrogenados dos fenos dos capins-braquiária decumbens e jaraguá, colhidos no estádio de maturação das sementes e submetidos à amonização com produtos químicos e uma fonte vegetal de urease.

\section{Material e Métodos}

O experimento foi conduzido na seguindo a mesma metodologia descrita no trabalho conduzido por REIS et al. (2001).

Após o período de tratamento de dois meses (04 de julho de 1997), as pilhas de fardos foram abertas e, depois de três dias de aeração, para eliminação da amônia que não reagiu com a fração fibrosa, foram recolhidas amostras para se realizarem as avaliações químicas.

As amostras coletadas foram congeladas e, a seguir, moídas, evitando-se, dessa forma, as perdas de nitrogênio amoniacal durante a secagem em estufa.

Os teores de nitrogênio total foram dosados segundo as técnicas descritas por SILVA (1990). Os valores de nitrogênio insolúvel em detergente neutro (NIDN) e nitrogênio insolúvel em detergente ácido (NIDA) foram determinados nos resíduos obtidos após o tratamento das amostras, respectivamente, com detergentes neutro ou ácido, observando-se os procedimentos preconizados por PEREIRA e ROSSI JR. (1994).

Os conteúdos de nitrogênio não-protéico (NNP) foram determinados por precipitação do $\mathrm{N}$ com ácido tricloroacético, segundo procedimentos da ASSOCIATION OF OFFICIAL ANALYTICAL CHEMISTS - AOAC (1984), e os de N amoniacal, de acordo com as técnicas de BREMNER e KEENEY (1965), em câmara de distilação de um microdestilador Kjeldahl modificado (BREMNER, 1965).

Os dados obtidos do arranjo fatorial composto por dois tipos de volumosos (fenos dos capins-braquiária decumbens e jaraguá), submetidos aos quatro tratamentos (controle, aplicação de uréia, aplicação de uréia mais labe-labe e aplicação de amônia anidra), foram analisados segundo o delineamento em blocos casualizados com quatro repetições, considerando como bloco as camadas de fardos dentro das pilhas, e as comparações entre médias foram realizadas pelo teste Tukey, a 5\% de probabilidade.

\section{Resultados e Discussão}

Foram observados valores médios de NIDN (\%MS) de 0,28 e 0,41 e de NIDA (\%MS) de 0,24 e 0,34 , respectivamente para os fenos de braquiária decumbens e jaraguá. Teores médios de NIDN de 0,$22 ; 0,43,0,34 ;$ e 0,38 e de NIDA de 0,$21 ; 0,35 ; 0,30$; e 0,31 foram registrados, respectivamente, para os fenos não-tratados, tratados com uréia, tratados com uréia e labe-labe e tratados com amônia anidra.

Estes resultados foram semelhantes aos observados por MASON et al. (1989a, 1989b), os quais observaram que a aplicação de $\mathrm{NH}_{3}$ ou de uréia pode aumentar a retenção de $\mathrm{N}$ na parede celular, principalmente quando o tratamento é efetuado sob altas temperaturas. Da mesma forma, REIS et al. (1990b, 1991) e ROSA e REIS (1995) registraram aumento nos valores de $\mathrm{N}$ retido na parede celular, quando trataram fenos de gramíneas tropicais com $\mathrm{NH}_{3}$ ou com uréia, sob temperatura ambiente.

É importante registrar que a diferença entre os valores de NIDN e NIDA corresponde à fração B3, ou seja, a proteína associada à parede celular de degradabilidade lenta (KRISHNAMOORTHY et al., 1982; VAN SOEST e FOX, 1992).

Foram observados no presente estudo valores de NIDN menos NIDA de 0,01;0,08;0,04; e 0,07\%, respectivamente, para os fenos não-tratados, trata- 
684 Rev. bras. zootec.

dos com uréia, uréia mais labe-labe e amônia anidra, respectivamente.

A amonização acarretou diminuição acentuada $(\mathrm{P}<0,05)$ nas relações NIDN/NT e NIDA/NT (Tabela 1) dos fenos dos capins-braquiária decumbens e jaraguá, observando-se menores valores para os fenos tratados com uréia mais labe labe ou com amônia anidra. A aplicação de $\mathrm{NH}_{3}$ e de uréia aumentou $(\mathrm{P}<0,05)$ os conteúdos de NNP e de $\mathrm{N}$ amoniacal e as relações NNP/NT e NA/NT (Tabela 2), causando o diminuição nas relações NIDN/NT e NIDA/NT dos fenos.

Os aumentos nas relações NNP/NT e NA/NT evidenciam a retenção do $\mathrm{N}$ aplicado nas formas de nitrogênio não-protéico e $\mathrm{N}$ amoniacal (Tabela 2). As maiores retenções $(\mathrm{P}<0,05)$ de NNP e NA foram observadas nos fenos submetidos à amonização (Tabela 2).

A diferença entre os teores de NNP e NA (Tabela 2) pode estar relacionada com os compostos nitrogenados formados devido à reação do $\mathrm{N}$ adicionado com a hemicelulose solubilizada, formando amidas (BUETTNER et al., 1982; BARTON II et al., 1986).

Segundo SUNDSTOL e COXWORTH (1984) e BERGER et al. (1994), as principais formas de retenção do N aplicado por amonização são as de $\mathrm{N}$ solúvel em água, NNP e N amoniacal. De acordo com DRYDEN e KEMPTON (1984), 67\% do N aplicado na palha de cevada foi retido na forma de NNP e $11,5 \%$, na parede celular. De maneira semelhante, ROSA e REIS (1995) observaram valores de retenção do N aplicado na forma de NNP de 73,6 e 81,2\%, enquanto 41,6 e $41,4 \%$ do $\mathrm{N}$ foi retido como $\mathrm{N}$ amoniacal, valores referentes à aplicação de $\mathrm{NH}_{3}$ ou de uréia no feno de braquiária decumbens.

$\mathrm{O}$ nitrogênio retido como NNP ou como $\mathrm{N}$ amoniacal corresponde à fração $\mathrm{A}$, ou seja, tem alta taxa de degradação ruminal, estando prontamente disponível para os microrganismos do rúmen (SNIFFEN et al., 1992; VAN SOEST e FOX, 1992).

Considerando os baixos conteúdos de $\mathrm{PB}$ dos fenos não-tratados (Tabela 3), pode-se afirmar que os teores da fração B, proteína verdadeira (SNIFFEN et al., 1992), foram baixos.

Observaram-se aumentos médios $(\mathrm{P}<0,05)$ nos teores de PB de 7,6; 7,9; e 8,1 unidades percentuais (Tabela 03), respectivamente, para os fenos tratados com uréia, uréia mais labe-labe ou amônia anidra.

Os aumentos nos teores de PB foram resultado da retenção do $\mathrm{N}$ aplicado de 48,4; 50,3; e 52,7\%, respectivamente para os fenos tratados com uréia, uréia e labe-labe ou amônia anidra. Deve-se salientar que as amostras utilizadas para as análises químicas foram colhidas três dias após a abertura das pilhas de fardos. Assim, o N dosado refere-se ao efetivamente retido na fração fibrosa, ou aquele que reagiu com a

Tabela 1 - Valores de compostos nitrogenados dos fenos de braquiária decumbens e jaraguá não-tratados (NT), tratados com uréia (U - 5,4\% MS), uréia (UL - 5,4\% MS) mais labe-labe (3,0\% MS) ou amônia anidra $\left(\mathrm{NH}_{3}-3,0 \% \mathrm{MS}\right)$

Table 1 - Nitrogen compounds evaluated on braquiaria decumbens and jaragua hays non treated (NT), treated with urea (U-5.4\% DM), urea (UL - 5.4\% DM) and lab lab (3.0\% DDM) or anhydrous ammonia $\left(\mathrm{NH}_{3}-3.0 \% \mathrm{DM}\right)$

\begin{tabular}{|c|c|c|c|c|c|}
\hline \multirow[b]{2}{*}{$\begin{array}{l}\text { Feno } \\
\text { Hay }\end{array}$} & \multicolumn{4}{|c|}{$\begin{array}{l}\mathrm{N} \text { insolúvel em detergente neutro/N total } \\
\text { Neutral detergent insoluble N/Total N }\end{array}$} & \multirow[b]{2}{*}{$\begin{array}{l}\text { Média } \\
\text { Mean }\end{array}$} \\
\hline & NT & $\mathrm{U}$ & UL & $\mathrm{NH}_{3}$ & \\
\hline B. decumbens & $64,4^{\mathrm{Aa}}$ & $25,9^{\mathrm{Bb}}$ & $20,6^{\mathrm{Bc}}$ & $19,1^{\mathrm{Bc}}$ & 32,5 \\
\hline Jaraguá & $64,5^{\mathrm{Aa}}$ & $34,5^{\mathrm{Ab}}$ & $25,8^{\mathrm{Ac}}$ & $26,1^{\mathrm{Ac}}$ & 37,7 \\
\hline Média & 64,4 & 30,2 & 23,2 & 22,5 & \\
\hline \multicolumn{6}{|l|}{ Mean } \\
\hline \multirow[t]{2}{*}{$\mathrm{CV}(\%)$} & 8,2 & & & & \\
\hline & \multicolumn{4}{|c|}{$\begin{array}{l}\mathrm{N} \text { insolúvel em detergente ácido/ } \mathrm{N} \text { total } \\
\text { Acid detergent insoluble N/Total } N\end{array}$} & \\
\hline $\begin{array}{l}\text { Feno } \\
\text { Hay }\end{array}$ & NT & $\mathrm{U}$ & UL & $\mathrm{NH}_{3}$ & $\begin{array}{l}\text { Média } \\
\text { Mean }\end{array}$ \\
\hline B. decumbens & 56,4 & 21,9 & 20,2 & 16,7 & $28,8^{\mathrm{B}}$ \\
\hline Jaraguá & 61,4 & 26,4 & 24,5 & 24,4 & $34,9^{\mathrm{A}}$ \\
\hline Média & $58,9^{\mathrm{a}}$ & $25,6^{\mathrm{b}}$ & $22,4^{\mathrm{c}}$ & $20,5^{\mathrm{c}}$ & \\
\hline \multicolumn{5}{|l|}{ Mean } & \\
\hline $\mathrm{CV}(\%)$ & 9,5 & & & & \\
\hline
\end{tabular}

Médias seguidas de mesmas letras, maiúsculas nas colunas e minúsculas nas linhas, não diferem $(P>0,05)$ pelo teste Tukey.

Means followed by the same letters, capital in the column and small in the row, are not different $(P>.05)$ Tukey test. 
REIS et al.

Table 2 - Valores de compostos nitrogenados dos fenos dos capins-braquiária decumbens e jaraguá não-tratados (NT), tratados com uréia (U-5,4\% MS), uréia (UL - 5,4\% MS) mais labe-labe (3,0\% MS), ou com amônia anidra $\left(\mathrm{NH}_{3}-3,0 \% \mathrm{MS}\right)$

Table 2 - Nitrogen compounds evaluated on braquiaria decumbens and jaragua hays non treated (NT), treated with urea (U - 5.4\% DM), urea (UL - 5.4\% DM) and lab lab (3.0\% DDM) or anhydrous ammonia $\left(\mathrm{NH}_{3}-3.0 \% \mathrm{DM}\right)$

\begin{tabular}{|c|c|c|c|c|c|}
\hline \multirow[b]{2}{*}{$\begin{array}{l}\text { Feno } \\
\text { Hay }\end{array}$} & \multicolumn{4}{|c|}{$\begin{array}{l}\mathrm{N} \text { não-protéico/ } \mathrm{N} \text { total } \\
\text { Non protein } N / \text { Total } N\end{array}$} & \multirow[b]{2}{*}{$\begin{array}{l}\text { Média } \\
\text { Mean }\end{array}$} \\
\hline & NT & $\mathrm{U}$ & UL & $\mathrm{NH}_{3}$ & \\
\hline B. decumbens & $38,2^{\mathrm{Ab}}$ & $91,3^{\mathrm{Aa}}$ & $94,4^{\mathrm{Aa}}$ & $96,9^{\mathrm{Aa}}$ & 80,2 \\
\hline Jaraguá & $15,4^{\mathrm{Bc}}$ & $81,2^{\mathrm{Bab}}$ & $85,2^{\mathrm{Ba}}$ & $74,6^{\mathrm{Bb}}$ & 64,1 \\
\hline Média & 26,8 & 86,2 & 89,8 & 85,7 & \\
\hline \multicolumn{6}{|l|}{ Mean } \\
\hline \multirow[t]{2}{*}{$\mathrm{CV}(\%)$} & 4,6 & & & & \\
\hline & \multicolumn{4}{|c|}{$\begin{array}{l}\text { N Amoniacal/N total } \\
\text { Amoniacal N/Total N }\end{array}$} & \\
\hline $\begin{array}{l}\text { Feno } \\
\text { Hay }\end{array}$ & NT & $\mathrm{U}$ & UL & $\mathrm{NH}_{3}$ & $\begin{array}{c}\text { Média } \\
\text { Mean }\end{array}$ \\
\hline B. decumbens & $8,0^{\mathrm{Ac}}$ & $45,4^{\mathrm{Aa}}$ & $43,5^{\mathrm{Aa}}$ & $32,4^{\mathrm{Ab}}$ & 32,3 \\
\hline Jaraguá & $4,7^{\mathrm{Ab}}$ & $30,1^{\mathrm{Ba}}$ & $30,8^{\mathrm{Ba}}$ & $27,4^{\mathrm{Ba}}$ & 23,2 \\
\hline Média & 6,3 & 37,8 & 37,1 & 29,9 & \\
\hline $\begin{array}{l}\text { Mean } \\
\text { CV }(\%)\end{array}$ & 10,7 & & & & \\
\hline
\end{tabular}

MMédias seguidas de mesmas letras, maiúsculas nas colunas e minúsculas nas linhas, não diferem $(P>0,05)$ pelo teste Tukey.

Means followed by the same letters, capital in the column and small in the row, are not different $(P>.05)$ Tukey test.

água contida na forragem ou com a adicionada durante o tratamento com uréia.

Estes valores foram próximos aos observados por REIS et al. (1990a; 1991) e ROSA e REIS (1995), que registraram valores de retenção de $\mathrm{N}$ de 50,8 e $53,6 \%$, quando trataram o feno de braquiária decumbens com $\mathrm{NH}_{3}$ ou com uréia, respectivamente.

De maneira semelhante ao observado por REIS et al. (2001), pode-se afirmar que a solubilização das frações FDN e hemicelulose e o aumento do conteúdo de $\mathrm{N}$ disponível (Tabela 2 ) resultaram em elevação na DIVVMS dos fenos tratados. Durante o tratamento químico dos fenos, não ocorreram temperaturas superiores a $50^{\circ} \mathrm{C}$ (REIS et al., 2001). Assim, pode-se admitir que, provavelmente, não ocorreram as reações de Maillard, o que pode ser confirmado pelos baixos valores de NIDA observados nos fenos tratados, além do decréscimo nos

Tabela 3 - Teores de proteína bruta (PB) dos fenos dos capins-braquiária decumbens e jaraguá não-tratados (NT), tratados com uréia (U - 5,4\% MS), uréia (UL - 5,4\% MS) mais labe-labe $(3,0 \% \mathrm{MS})$ ou amônia anidra $\left(\mathrm{NH}_{3}-3,0 \% \mathrm{MS}\right)$

Table 3 - Crude protein (CP) values evaluated on braquiaria decumbens and jaragua hays non treated (NT), treated with urea (U - 5.4\% DM), urea (UL - 5.4\% DM) and lab lab (3.0\% DM) or anhydrous ammonia $\left(\mathrm{NH}_{3}-3.0 \% \mathrm{DM}\right)$

\begin{tabular}{|c|c|c|c|c|c|}
\hline \multirow[b]{2}{*}{$\begin{array}{l}\text { Feno } \\
\text { Hay }\end{array}$} & \multicolumn{4}{|c|}{$\begin{array}{l}\mathrm{PB}(\% \mathrm{MS}) \\
C P(\% D M)\end{array}$} & \multirow[b]{2}{*}{$\begin{array}{c}\text { Média } \\
\text { Mean }\end{array}$} \\
\hline & NT & $\mathrm{U}$ & $\mathrm{UL}$ & $\mathrm{NH}_{3}$ & \\
\hline B. decumbens & $2,1^{\mathrm{Ab}}$ & $8,9^{\mathrm{Ba}}$ & $9,7^{\mathrm{Aa}}$ & $8,6^{\mathrm{Ba}}$ & 7,3 \\
\hline Jaraguá & $2,2^{\mathrm{Ab}}$ & $10,4^{\mathrm{Aa}}$ & $10,6^{\mathrm{Aa}}$ & $11,8^{\mathrm{Aa}}$ & 8,7 \\
\hline Média & 2,1 & 9,7 & 10,0 & 10,2 & \\
\hline \multicolumn{6}{|l|}{ Mean } \\
\hline $\mathrm{CV}(\%)$ & 11,0 & & & & \\
\hline
\end{tabular}

Médias seguidas de mesmas letras, maiúsculas nas colunas e minúsculas nas linhas, não diferem $(P>0,05)$ pelo teste Tukey.

Means followed by the same letters, capital in the column and small in the row, are not different (P>.05) Tukey test. 
teores de lignina observados nos fenos tratados com $\mathrm{NH}_{3}$. Além disso, pode-se observar que o $\mathrm{N}$ aplicado foi retido, principalmente, nas formas de NNP e N amoniacal.

\section{Conclusões}

A amonização nas doses utilizadas aumentou o conteúdo de nitrogênio disponível para o processo de digestão.

A uréia como fonte de amônia teve a mesma eficiência em alterar a composição química, quando comparada à amônia anidra.

A adição do labe-labe como fonte adicional de urease não aumentou a eficiência da uréia no tratamento dos volumosos.

\section{Referências Bibliográficas}

ASSOCIATION OF OFFICIAL ANALYTICAL CHEMISTS AOAC. 1984. Official methods of analysis. 14.ed. Arlington, Virginia. 1141p.

BARTON II, F.E., WOLSINK, J.H., VEDDER, H.M. 1986. Near infrared reflectance spectroscopy of untreated and ammoniated barley straw. Anim. Feed Sci. and Technol., 15(1):189-196.

BERGER, L.L., FAHEY JR., G.C., BOURQUIM, L.O et al. 1994. Modification of forage quality after harvest. In: FAHEY JR. G.C. et al. (Eds.). Forage quality, evaluation e utilization. Madison: American Society of Agronomy. p.922-966.

BREMNER, J.M. 1965. Inorganic forms of nitrogen. In: BLACK, C.A. Methods of soil analysis: part 2. Madison: American Society of Agronomy. 1572p. (Agronomy, 9).

BREMNER, J.M., KEENEY, D.R.1965. Steam-distillation methods for determination of ammonium, nitrate e nitrite. In: Black, C.A. Methods of soil analysis: part 2. Madison: American. Society. of Agronomy. 1572p. (Agronomy, 9).

BUETTNER, M.R., LECHTENBERG, V.L., HENDRIX, K.S., et al.1982. Composition and digestion of ammoniated tall fescue (Festuca arundinacea Schreb.) hay). J. Anim. Sci., 54(1):173-178.

DRYDEN, G.M., KEMPTON, J.J.1984. Digestion of organic matter and nitrogen in ammoniated barley straw. Anim. Feed Sci. Technol., 10(1):65-75.

KRISHNAMOORTHY, U., MUSCATO, T.V., SNIFFEN, CJ., et al. 1982. Nitrogen fraction in selected feedstuffs. J. Dairy Sci., 65(2):217-225.

MASON, V.C., DHANOA, M.S., HARTLEY, R.D. et al.1989a. Relationships between chemical composition, digestibility in vitro and cell wall degradability of wheat straw treated with different amounts of ammonia and at elevated temperature. Anim. Feed Sci. Technol., 24(3-4):293-306.
MASON, V.C., KEENE, A.S., COOK, J.E. et al. 1989b. Oven and stack ammoniation of grass hays. 1. Changes in chemical composition in relation to digestibility in vitro and cell wall degradability. Anim. Feed Sci. Technol., 24(3-4):299-311.

PEREIRA, J.R.A., ROSSI JR., P. 1994. Manual de avaliação nutricional de alimentos. Piracicaba, FEALQ. 34p.

REIS, R.A., GARCIA, R., QUEIROZ, A.C. et al. 1991. Efeitos da amonização sobre a qualidade dos fenos de gramíneas tropicais. Pesq. Agropec. Bras., 26(8):1183-1191.

REIS, R.A., GARCIA, R., QUEIROZ, A.C. et al. 1990a. Efeitos da aplicação de amônia anidra sobre a composição química e digestibilidade in vitro dos fenos de três gramíneas forrageiras de clima tropical. R. Soc. Bras. Zootec., 19(3):219-224.

REIS, R.A., GARCIA, R., SILVA, D.J. et al. 1990b. Efeitos da aplicação de amônia anidra sobre a digestibilidade do feno do capim-braquiária (Brachiaria decumbens Stapf). R. Soc. Bras. Zootec., 19(3):201-208.

REIS, R.A., RODRIGUES, L.R.A., PEREIRA, J.R.A. et al. 2001. Avaliação de fontes de amônia para o tratamento de fenos de gramíneas tropicais. 1. Constituintes da parede celular, poder tampão e atividade ureática. Rev. bras. zootec., 30(3):674-681.

ROSA, B., REIS, R.A. 1995. Valor nutritivo dos fenos de Brachiaria decumbens Stapf cv. Basilisk amonizados: Fracionamento do nitrogênio. In: REUNIÃO ANUAL DA SOCIEDADE BRASILEIRA DEZOOTECNIA, 32, Brasília. Anais... Brasília: SBZ, 1995. p.86-87.

SILVA, D.J. 1990. Análise de alimentos (métodos químicos e biológicos), 2.ed., Viçosa: UFV. 165p.

SNIFFEN, C.J., O'CONNOR, J.D., VAN SOEST, P.J. et al. 1992. A net carbohydrate and protein system for evaluating cattle diets: 11. Carbohydrate and protein availability. J. Anim. Sci., 70(10):3562-3577.

SUNDSTOL, F., COXWORTH, E.M.1984. Ammonia treatment. In: SUNDSTOL, F., OWEN, E. (Eds.) Straw and others fibrous by-products as feed. Amsterdam: Elsevier Press. p.196-247.

VAN SOEST, P.J., FOX, D.G. Discounts for net energy and protein-fifth revision. In: CORNELL NUTRITIONAL CONFERENCE, 1992. Proceedings... Ithaca: University of Cornell, 1992. p.40-68.

WILLIAMS, P.E.V., INNES, G.M., BREWER, A. 1984a. Ammonia treatment of straw via the hydrolysis of urea. I. Effects of dry matter and urea concentrations on the rate of hydrolysis of urea. Anim. Feed Sci. Technol., 11(2):103-113.

WILLIAMS, P.E.V., INNES, G.M., BREWER, A. 1984b. Ammonia treatment of straw via hydrolysis of urea. II. Additions of soya bean (urease), sodium hydroxide and molasses; effects on the digestibility of urea-treated straw. Anim. Feed Sci. Technol., 11(2):115-124.

Recebido em: $02 / 05 / 00$

Aceito em: 11/12/00 